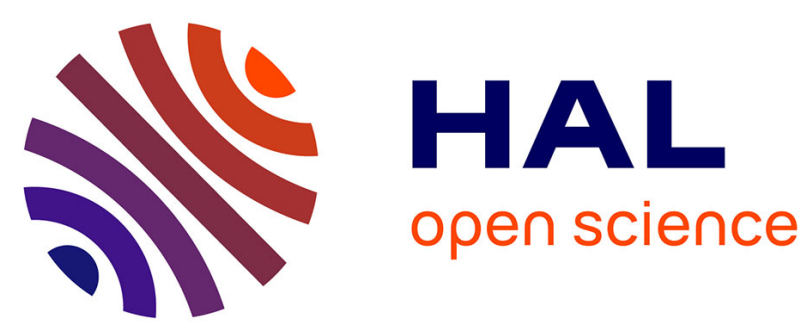

\title{
Nomograms to predict late urinary toxicity after prostate cancer radiotherapy.
}

Romain Mathieu, Juan David Ospina Arango, Véronique Beckendorf, Jean-Bernard Delobel, Taha Messai, Ciprian Chira, Alberto Bossi, Elisabeth Le Prisé, Stéphane Guerif, Jean-Marc Simon, et al.

\section{To cite this version:}

Romain Mathieu, Juan David Ospina Arango, Véronique Beckendorf, Jean-Bernard Delobel, Taha Messai, et al.. Nomograms to predict late urinary toxicity after prostate cancer radiotherapy.. World Journal of Urology, 2013, 32 (3), pp.743-51. 10.1007/s00345-013-1146-8 . inserm-00911324

\section{HAL Id: inserm-00911324 https://www.hal.inserm.fr/inserm-00911324}

Submitted on 7 Jul 2014

HAL is a multi-disciplinary open access archive for the deposit and dissemination of scientific research documents, whether they are published or not. The documents may come from teaching and research institutions in France or abroad, or from public or private research centers.
L'archive ouverte pluridisciplinaire HAL, est destinée au dépôt et à la diffusion de documents scientifiques de niveau recherche, publiés ou non, émanant des établissements d'enseignement et de recherche français ou étrangers, des laboratoires publics ou privés. 
1 Nomograms to predict late urinary toxicity after prostate cancer radiotherapy

2

3 Romain Mathieu* a, Juan David Ospina Arango b, Véronique Beckendorf c, Jean-

4 Bernard Delobel d, Taha Messai e, Ciprian Chira d, Alberto Bossi e, Elisabeth Le

5 Prisé d, Stéphane Guerif f, Jean-Marc Simon g, Bernard Dubray h, Jian Zhu b, Jean-

6 Léon Lagrange i, Pascal Pommier j, Khemara Gnep d, Oscar Acosta b, Renaud de

7 Crevoisier b,d.

8

9 a. Dept. of Urology, Centre Hospitalier Universitaire Pontchaillou, Rennes, France

10 b. Inserm U1099, LTSI, Rennes, France

11 c. Centre Alexis Vautrin, Vandoeuvre les Nancy, France

12 d. Centre Eugene Marquis, Rennes, France

e. Institut Gustave-Roussy, Villejuif, France

f. Centre Hospitalier Universitaire, Poitiers, France

g. Hôpital de la Pitié-Salpétrière, Paris, France

h. Centre Henry Becquerel, Rouen, France

i. Hôpital Henry Mondor, Créteil, France

j. Centre Léon Berard, Lyon, France

word count of the text: 2396

word count of the abstract: 244

24 Keywords : late urinary toxicity, predictive models, nomograms, prostate cancer, 25 radiotherapy. 
26 Correspondance to:

27 Romain Mathieu

28 Service d'Urologie

29 Centre Hospitalier Universitaire de Rennes

30 2, rue Henri Le Guilloux

3135033 Rennes Cedex

32 Phone: + 33663697030

33 Fax: +33299284113

34 e-mail: romainmath@yahoo.fr 


\section{Abstract}

Objective: To analyze late urinary toxicity after prostate cancer radiotherapy (RT): symptom description and identification of patient characteristics or treatment parameters allowing for the generation of nomograms.

Methods: 965 patients underwent RT in seventeen French centers for localized prostate cancer. Median total dose was 70 Gy (range, 65-80 Gy), using different fractionations ( 2 or 2.5 Gy/day) and techniques. Late urinary toxicity and the corresponding symptoms (urinary frequency, incontinence, Dysuria/decreased stream and hematuria) were prospectively assessed in half of the patients using the LENTSOMA classification. Univariate and multivariate Cox regression models addressed patient or treatment-related predictors of late urinary toxicity ( $\geq$ grade 2 ). Nomograms were built up and their performance was assessed.

Results : The median follow-up was 61 months. The 5-year ( $\geq$ grade 2 ) global urinary toxicity, urinary frequency, hematuria, dysuria and urinary incontinence rates were: $15 \%, 10 \%, 5 \%, 3 \%$ and $1 \%$, respectively. The 5 -year ( $\geq$ grade 3 ) urinary toxicity rate was $3 \%$. The following parameters significantly increased the 5 year risk of global urinary toxicity ( $\geq$ grade 2$)$ : anticoagulant treatment $(R R=2.35)$, total dose $(R R=1.09)$, age $(R R=1.06)$. Urinary frequency was increased by the total dose $(R R=1.07)$ and diabetes $(R R=4)$. Hematuria was increased by anticoagulant treatment $(R R=2.9)$. Dysuria was increased by the total dose $(R R=1.1)$. Corresponding nomograms and their calibration plots were generated. Nomogram performance should be validated with external data.

Conclusions: The first nomograms to predict late urinary toxicity but also specific urinary symptoms after prostate RT were generated, contributing to prostate cancer

60 treatment decision. 


\section{Introduction}

Radical prostatectomy (RP) and radiotherapy (RT) are cornerstones of localized prostate cancer treatment, leading to relatively similar results in terms of local control 1. However, the side effects of both are different, mainly concerning the urinary adverse events. If the intensity of this toxicity after RT is relatively well-reported in the literature, the description of the symptoms corresponding to this toxicity is often limited. Moreover, the patient and/or treatment factors related to each of the side effects are not well known. Their identification is crucial. These factors could be used to generate urinary toxicity predictive tools (like nomograms), to guide the physician in deciding the treatment and to inform the patient, in this context of different therapeutic alternatives. To identify which radiation parameters increase toxicity is essential in understand how to decrease toxicity, in particular due to new highlyconformal radiotherapy techniques, such as Intensity Modulated Radiation Therapy (IMRT) and Image Guided Radiation Therapy (IGRT).

These new techniques allow for an increase of the dose in the prostate considering the strong dose-effect relationship for local control ${ }^{2}$, while limiting the dose in the bladder and the rectum. Their part in decreasing urinary toxicity has not, however, been clearly shown. If the relationship between dose-volume and toxicity has been consistently demonstrated for the rectum, it remains unclear for the bladder 3,4 .

81 Moreover, hypofractionated RT may be more efficient in eradicating prostate 82 adenocarcinoma, but the impact of such modified fractionation on toxicity has not been well-established.

84 If nomograms have already been published to predict rectal bleeding and the risk of 85 fecal incontinence 5,6 , to our knowledge no tools have as yet been developed to 
predict urinary toxicity.

We thus analyzed a large group of patients having received prostate cancer RT using different radiation techniques, total doses and fractionations, to accurately quantify and describe late urinary toxicity, identify related risk factors and propose nomograms.

\section{Material and methods}

\subsection{Patient inclusion criteria}

Records from 965 patients who received definitive radiotherapy for localized prostate adenocarcinoma were analyzed. Data were prospectively collected from 470 patients treated in 17 French institutions within two randomized studies: GETUG 06 (comparing 70 Gy to $80 \mathrm{~Gy})^{7}$ and STIC-IGRT (testing IGRT) ${ }^{8}$, and retrospectively from 495 patients treated in two of them. All patients had a biopsy-proven adenocarcinoma of the prostate. Pretreatment workup included a CT scan and a bone scan.

\subsection{Patient and tumor characteristics}

The following data were extracted from each randomized database: age, medical and surgical history (prior abdominal surgery, prior transurethral resection of prostate, anticoagulant treatment, diabetes, hypertension, coronary insufficiency) and tumor characteristics (T stage, Gleason score, pretreatment PSA). Patients were staged by digital rectal examination according to the 1992 American Joint Committee on 
111 Cancer staging system ${ }^{9}$. Patients were classified into the three prognostic risk

112 groups defined by D'Amico ${ }^{1}$. Patient and tumor characteristics are presented in 113 Table 1.

\subsection{Treatment characteristics}

117 The target volume comprised the prostate only in the low risk group (16\%), the 118 prostate and the seminal vesicles in the other risk groups. The pelvic lymph nodes

119 were not treated in the two randomized studies, but may have been treated for high 120 risk patients of the two institutions (not treated in the randomized study) (9\%). The

121 median total dose of the prostate was $70 \mathrm{~Gy}$ (ranging from 65 Gy to $80 \mathrm{~Gy}$ ), the 122 seminal vesicles receiving $46 \mathrm{~Gy}$, and the pelvic lymph nodes also $46 \mathrm{~Gy}$, if treated.

123 Dose per fraction was 2 Gy/day, 5 fractions/week for $69 \%$ of patients, or 2.5 Gy/day, 1244 fractions/week for $31 \%$ of patients.

125 The radiation technique was 3D conformational for the vast majority of patients (85\%)

126 and $2 \mathrm{D}$ for $15 \%$ of the patients, depending on the treatment period. Intensity 127 Modulated RT (IMRT) and Image Guided RT (IGRT) have been more recently used 128 in patients receiving $80 \mathrm{~Gy}$. Among the $41 \%$ of the patients having received $80 \mathrm{~Gy}$, 129 the technique was a standard 3D conformal RT for $63 \%$, IMRT only for $18 \%$ and 130 IMRT combined with IGRT in $19 \%$.

131 The 3D radiation technique was carried out following the French GETUG group

132 recommendations, as previously reported ${ }^{7}$. Patients underwent simulation and 133 treatment in the supine position. Target volume and organs at risk (bladder, rectum 134 and femoral heads) were delineated on CT slices. A bladder wall was generated with 135 a thickness of $7 \mathrm{~mm}$ from the external manually-delineated bladder contour according 
136 GETUG recommandations. The planning target volume (PTV) was calculated by

137 adding a 10-mm margin in all directions except in the posterior where a 5-mm margin

138 was considered. The dose-volume histogram had to respect the GETUG constraints

1397 . The following bladder dosimetric data were analyzed: volume of the bladder wall,

140 Dmax (maximal dose received in the bladder), D25 (minimal dose received in $25 \%$ of

141 the bladder wall) and D50 (minimal dose received in 50\% of the bladder wall).

142 Androgen deprivation therapy was given to $23 \%$ of the patients, all presenting a high

143 risk cancer.

144 Details of treatment characteristics are presented in Table 1.

\subsection{Follow up and toxicity grading}

148 According to the protocol of surveillance, patients were evaluated every three months

149 for a year and every 6 months thereafter Late urinary toxicity was defined as events 150 occurring more than six months after the beginning of RT. To determine the severity 151 and incidence of main late urinary complaints, records were prospectively extracted

152 from trials database or retrospectively from physicians' reports, at each follow-up 153 visit. Urinary complaints were classified according to the LENTSOMA morbidity 154 scoring system into four categories of symptoms: urinary frequency, dysuria, 155 incontinence and hematuria (Table 2). Dysuria and decreased stream were 156 considered as a single symptom. The analyses were performed for late urinary

157 toxicity and for each of the symptoms, all being considered if $\geq$ grade 2 .

\subsection{Statistical analysis}


161 The impact of the following parameters on late urinary toxicity ( $\geq$ grade 2 ) was tested

162 at the 5-years mark:

163 - Patient parameters: age, diabetes (types 1 and 2), anticoagulant treatment 164 (vitamin $\mathrm{K}$ antagonist or antiplatelet drug), prior abdominal or pelvic surgery, 165 prior transurethral resection of prostate, hypertension, coronary insufficiency;

166 - Tumor parameters: Gleason Score, T stage, prognostic group (D'amico);

167 - Treatment parameters: RT technique (2D technique, 3DConformational 168 technique, with or without IMRT/IGRT), total dose and fractionation, target 169 volume, dosimetric bladder parameters (volume of the bladder wall, maximal 170 dose, D25, D50) and androgen deprivation.

171 The data-recording modality (prospective versus retrospective collection) was 172 verified as having no significant impact on the risk of toxicity.

173 The Kaplan-Meier method was used to calculate cumulative incidences of late 174 urinary toxicity events ( $\geq$ grade 2 ). The differences between the survival curves 175 were assessed using the log-rank test. Relationships between late urinary toxicity 176 and patient, tumor or treatment parameters were first analyzed using Cox 177 proportional hazard regression at univariate level. Multivariate analyses, including 178 covariates statistically significant in univariate analysis, were carried out using the 179 Cox proportional hazards model. The 5-year late urinary toxicity events were 180 analyzed using logistic regression at univariate and multivariate levels. A p-value $181 \leq 0.05$ was considered statistically significant. Nomograms to predict 5 -year late 182 urinary toxicity and specific symptoms were built up according to the logistic 183 model. To assess nomogram performance, a nonparametric fit of the predicted 184 probability as regards the actual observed probability was made for each 185 nomogram. The analyses were performed using the SPSS V18 (Chicago, IL) and 
$\mathrm{R}$ with the rms package. Non-parametric tests were used to compare the distribution of the parameters between different groups of treatment.

\section{Results}

The median follow-up was 61 months (range 6-206).

192

\subsection{Late urinary toxicity: global quantification and symptom description}

Among the 965 patients, 183 events of late urinary toxicity grade 2 or greater were reported. Among them, only $14 \%$ were toxicity grade 3 or 4 . Ninety-two $(50 \%)$ corresponded to an increase in urinary frequency, $36(20 \%)$ to dysuria, and $48(26 \%)$ to hematuria. Only seven consisted of urinary incontinence grade 2 or greater. The 5year and 10-year rates of grade 2 or higher urinary toxicity, urinary frequency, 200 hematuria, dysuria and urinary incontinence were: $15 \%(95 \% \mathrm{Cl}: 12 \%-18 \%)$ and $24 \%$ 201 (95\%Cl:19\%-29\%), 10\% (95\%Cl: 8\%-12\%) and 15\% (95\%Cl:11\%-19\%), 5\% (95\% $202 \mathrm{Cl}: 4-6 \%)$ and $8 \%(95 \% \mathrm{Cl}: 5 \%-11 \%), 3 \%(95 \% \mathrm{Cl}: 2 \%-4 \%)$ and $8 \%(95 \% \mathrm{Cl}: 4 \%-12 \%)$, and $1 \%(95 \% \mathrm{Cl}: 0 \%-2 \%)$ and $2 \%(95 \% \mathrm{Cl}: 0 \%-4 \%)$, respectively. Figure 1 presents cumulative incidence of global late urinary toxicity and the corresponding symptoms ( $\geq$ grade 2 ). The 5 and 10 -year rates of grade 3 or higher global urinary toxicity were $3 \%(95 \% \mathrm{Cl}: 2 \%-4 \%)$ and $7 \%(95 \% \mathrm{Cl}: 5 \%-9 \%)$.

\subsection{Nomograms to predict five-year late toxicity}

210 In multivariate analysis, the following pre-planning parameters significantly positive 
211 associated to the 5-year risk of urinary toxicity: anticoagulant treatment $(R R=2.35)$,

212 total dose $(R R=1.09)$, age $(R R=1.06), D 25(R R=1.03)$, and Dmax $(R R=1.1)$ received

213 by the bladder (Table 3). Nomogram including pre-treament factors to predict 5-year

214 risk of global late urinary toxicity (and its calibration plot) is presented in Figure 2.

215 The 5-year risk of urinary frequency was related to total dose $(R R=1.07)$ and

216 diabetes $(R R=4)$. For dysuria, the total dose was the only significant factor $(R R=1.1)$

217 (Table 3). Figures 3 and 4 present nomograms to predict the 5-year risk of these 218 urinary symptoms. The 5-year risk of hematuria was significantly increased by

219 anticoagulant treatment $(\mathrm{RR}=2.9)$

\section{Discussion}

222 We showed that the incidence of late urinary toxicity symptoms continuously 223 increases after RT, reaching a rate of $24 \%$ and $7 \%$ at 10 years, for more than grade 2242 and grade 3 urinary toxicity, respectively. These rates appear relatively similar to 225 those previously observed after $\mathrm{RT}^{7}$. Urinary toxicity events may occur late after RT, later than those observed for late gastro-intestinal toxicity which generally reaches a

227 plateau at three years after RT ${ }^{10}$. A longer follow-up is consequently required to 228 properly estimate late urinary toxicity ${ }^{10}$. Comparing the risk of urinary toxicity after 229 different treatments should therefore carefully consider the same follow-up. Late 230 urinary toxicity symptoms are mainly characterized by urinary frequency (50\% of all 231 events) and, to a lesser extent, by dysuria and hematuria. Incontinence is very rare $232(<2 \%$ at 10 years $)$.

233 We identified age, diabetes and anticoagulant treatment as factors increasing the risk 234 of late urinary toxicity by multivariate analysis. Diabetes has already been reported 235 as a strong predictor of late urinary toxicity in prostate cancer radiotherapy ${ }^{11}$. The 
236 fact that anticoagulation or antiplatelet agents increase the risk of late urinary toxicity

237 after prostate cancer radiotherapy has rarely been reported, even if this association 238 concerns the risk of late rectal toxicity ${ }^{12,13}$. However, anticoagulation has been 239 already associated with gross hematuria in the whole population and could be an 240 independent risk factor of urinary complaints whatever a radiation is performed. Age 241 and diabetes have been previously associated with urinary side effects after radical 242 prostatectomy, especially urinary incontinence ${ }^{14,15}$. Thus, their implications in urinary 243 toxicity after RT should not be underestimated in treatment decision.

244 We found a strong dose-effect relationship in urinary toxicity (global toxicity, urinary 245 frequency and dysuria). Most of the randomized studies comparing a "standard" dose 246 (68 to $70 \mathrm{~Gy}$ ) to a higher one (76 to $80 \mathrm{~Gy}$ ) did not demonstrate such a significant 247 increase in late urinary toxicity ${ }^{16-19}$. However, in a large group of patients who 248 received a dose escalation with 3D-CRT/IMRT, Zelefsky et al reported a significant 249 increase of genitourinary (GU) toxicities after 10 years in patients who received 250 higher doses ${ }^{20}$. More recently, the GETUG 06 randomized trial reported such an 251 increase, when escalating the dose from $70 \mathrm{~Gy}$ to $80 \mathrm{~Gy}^{7}$. These differences can be 252 explained by several reasons. The first one is the lack of follow-up. Indeed, the initial 253 MDACC report that compared $78 \mathrm{~Gy}$ to $70 \mathrm{~Gy}$ did not show a significant difference in 254 late GI toxicity, while it was found with a longer follow-up ${ }^{16}$. Secondly, studies might 255 be different in terms of their treatment scheme (dose, target volume, technique), 256 patient characteristics and grading scale. Finally, urinary toxicity might be more 257 related to patient risk factors than dose parameters. The lack of correlation between 258 dose distribution (dose-volume histogram) and urinary toxicity may also be due to the 259 large bladder volume variation occurring at the planning stage and at the different 
260 fractions, so that the planned dose distribution does not represent the actual 261 delivered dose to the bladder.

262 A moderate hypofractionned schedule $(2.5 \mathrm{~Gy} / \mathrm{fr})$ in our series did not increase late 263 urinary toxicity. These results are concordant with contemporary studies ${ }^{21}$ and 264 emphasize the interest of hypofractionated schedule in prostate cancer radiotherapy. 265 IMRT and IGRT aim at increasing local control by allowing dose escalation, while 266 reducing toxicity by sparing normal surrounding tissues. Compared to "standard" 3D 267 conformal technique, IMRT clearly reduces the risk of long-term rectal toxicity and 268 bowel dysfunction $20,22,23$. However, IMRT fails to decrease late urinary toxicity in 269 most studies, as in the present one. Late urinary toxicity could even be partly due to 270 prostatic urethra lesions ${ }^{24}$, and modern techniques such as IMRT combined with 271 IGRT still do not allow for the preservation of this area. A recent non-randomized 272 study of Zelefsky et al reported however that, with a median follow-up of 2.8 years 273 and a high dose (86.4 Gy) delivered to the prostate by IMRT, patients treated with 274 IGRT (using fiducials) experienced significantly less urinary toxicity than non-IGRT 275 treated patients ${ }^{25}$.

276 Based on this predictive factors, we propose the first nomograms to predict late 277 urinary toxicity after radiation therapy. Indeed, many treatments now provide long 278 term survival and the decision of the patient concerning his own treatment is mainly 279 based on expected side effects. These nomograms have been built up according to 280 the pre-treatment parameters, available before any CT simulation, in order to help 281 physician and patient in the decision concerning the different prostate cancer 282 treatments. Consequently, we believe that the corresponding nomograms concerning 283 toxicity after radical prostatectomy should be proposed.

284 One limitation of our study is that both prospective and retrospective data (from 2 
285 institutions) were used to assess our nomograms. However, the effect of data being 286 retrospectively collected was not found to significantly impact on toxicity risk. 287 Furthermore, a large number of patients was necessary to identify a maximum 288 number of reliable toxicity predictors. Finally, nomogram performance has been 289 validated within our series but should be also confirmed using external data.

\section{Conclusions}

292

293 We were able to identify several parameters increasing the risk of urinary toxicity 294 after prostate cancer radiotherapy. The first nomograms to predict global late urinary 295 toxicity and corresponding symptoms were generated, resulting in new tools for 296 patient management and treatment decision, particularly between RT and surgery. 
298 Aknowledgements: Marian LEE for her critical review.

299 
1. D'Amico, A. V., Whittington, R., Malkowicz, S. B. et al.: Biochemical outcome after radical prostatectomy, external beam radiation therapy, or interstitial radiation therapy for clinically localized prostate cancer. JAMA, 280: 969, 1998

2. Cheung, R., Tucker, S. L., Lee, A. K. et al.: Dose-response characteristics of low- and intermediate-risk prostate cancer treated with external beam radiotherapy. Int J Radiat Oncol Biol Phys, 61: 993, 2005

3. Fiorino, C., Valdagni, R., Rancati, T. et al.: Dose-volume effects for normal tissues in external radiotherapy: pelvis. Radiother Oncol, 93: 153, 2009

4. Budaus, L., Bolla, M., Bossi, A. et al.: Functional outcomes and complications following radiation therapy for prostate cancer: a critical analysis of the literature. Eur Urol, 61: 112

5. Valdagni, R., Kattan, M. W., Rancati, T. et al.: Is it time to tailor the prediction of radio-induced toxicity in prostate cancer patients? Building the first set of nomograms for late rectal syndrome. Int J Radiat Oncol Biol Phys, 82: 1957, 2012

6. Valdagni, R., Rancati, T., Fiorino, C.: Predictive models of toxicity with external radiotherapy for prostate cancer: clinical issues. Cancer, 115: 3141, 2009

7. Beckendorf, V., Guerif, S., Le Prise, E. et al.: 70 Gy versus 80 Gy in localized prostate cancer: 5-year results of GETUG 06 randomized trial. Int J Radiat Oncol Biol Phys, 80: 1056, 2011

8. de Crevoisier, R., Pommier, P., Bachaud, J. et al.: Image-guided Radiation Therapy (IGRT) in Prostate Cancer: Preliminary Results in Prostate Registration and Acute Toxicity of a Randomized Study. Int J Radiat Oncol Biol Phys, 75: 99, 2009

9. Beahrs, O. H.: American Joint Committee on Cancer: Manual for Staging of Cancer. 4th edition ed. Philadelphia, PA JB Lippincott 1992

10. Gardner, B. G., Zietman, A. L., Shipley, W. U. et al.: Late normal tissue sequelae in the second decade after high dose radiation therapy with combined photons and conformal protons for locally advanced prostate cancer. J Urol, 167: 123, 2002

11. Herold, D. M., Hanlon, A. L., Hanks, G. E.: Diabetes mellitus: a predictor for late radiation morbidity. Int J Radiat Oncol Biol Phys, 43: 475, 
12. Takeda, K., Ogawa, Y., Ariga, H. et al.: Clinical correlations between treatment with anticoagulants/antiaggregants and late rectal toxicity after radiotherapy for prostate cancer. Anticancer Res, 29: 1831, 2009

13. Choe, K. S., Jani, A. B., Liauw, S. L.: External beam radiotherapy for prostate cancer patients on anticoagulation therapy: how significant is the bleeding toxicity? Int J Radiat Oncol Biol Phys, 76: 755

14. Novara, G., Ficarra, V., D'Elia, C. et al.: Evaluating urinary continence and preoperative predictors of urinary continence after robot assisted laparoscopic radical prostatectomy. J Urol, 184: 1028, 2010

15. Teber, D., Sofikerim, M., Ates, M. et al.: Is type 2 diabetes mellitus a predictive factor for incontinence after laparoscopic radical prostatectomy? A matched pair and multivariate analysis. J Urol, 183: 1087, 2010

16. Pollack, A., Zagars, G. K., Starkschall, G. et al.: Prostate cancer radiation dose response: results of the $M$. D. Anderson phase III randomized trial. Int J Radiat Oncol Biol Phys, 53: 1097, 2002

17. Zietman, A. L., DeSilvio, M. L., Slater, J. D. et al.: Comparison of conventional-dose vs high-dose conformal radiation therapy in clinically localized adenocarcinoma of the prostate: a randomized controlled trial. JAMA, 294: 1233, 2005

18. Dearnaley, D. P., Sydes, M. R., Graham, J. D. et al.: Escalated-dose versus standard-dose conformal radiotherapy in prostate cancer: first results from the MRC RT01 randomised controlled trial. Lancet Oncol, 8: 475, 2007

19. Al-Mamgani, A., van Putten, W. L., Heemsbergen, W. D. et al.: Update of Dutch multicenter dose-escalation trial of radiotherapy for localized prostate cancer. Int J Radiat Oncol Biol Phys, 72: 980, 2008

20. Zelefsky, M. J., Levin, E. J., Hunt, M. et al.: Incidence of late rectal and urinary toxicities after three-dimensional conformal radiotherapy and intensitymodulated radiotherapy for localized prostate cancer. Int J Radiat Oncol Biol Phys, 70: 1124, 2008

21. Leborgne, F., Fowler, J.: Late outcomes following hypofractionated conformal radiotherapy vs. standard fractionation for localized prostate cancer: a nonrandomized contemporary comparison. Int J Radiat Oncol Biol Phys, 74: 1441, 2009

22. Namiki, S., Ishidoya, S., Ito, A. et al.: Five-year follow-up of healthrelated quality of life after intensity-modulated radiation therapy for prostate cancer. Jpn J Clin Oncol, 39: 732, 2009

23. Alicikus, Z. A., Yamada, Y., Zhang, Z. et al.: Ten-year outcomes of 
high-dose, intensity-modulated radiotherapy for localized prostate cancer.

24. Wallner, K., Roy, J., Harrison, L.: Dosimetry guidelines to minimize urethral and rectal morbidity following transperineal I-125 prostate brachytherapy. Int J Radiat Oncol Biol Phys, 32: 465, 1995 IGRT for the Treatment of Clinically Localized Prostate Cancer. Int J Radiat

409 Oncol Biol Phys, in press, 2012

410 


\section{$412 \quad$ Figure legends}

413

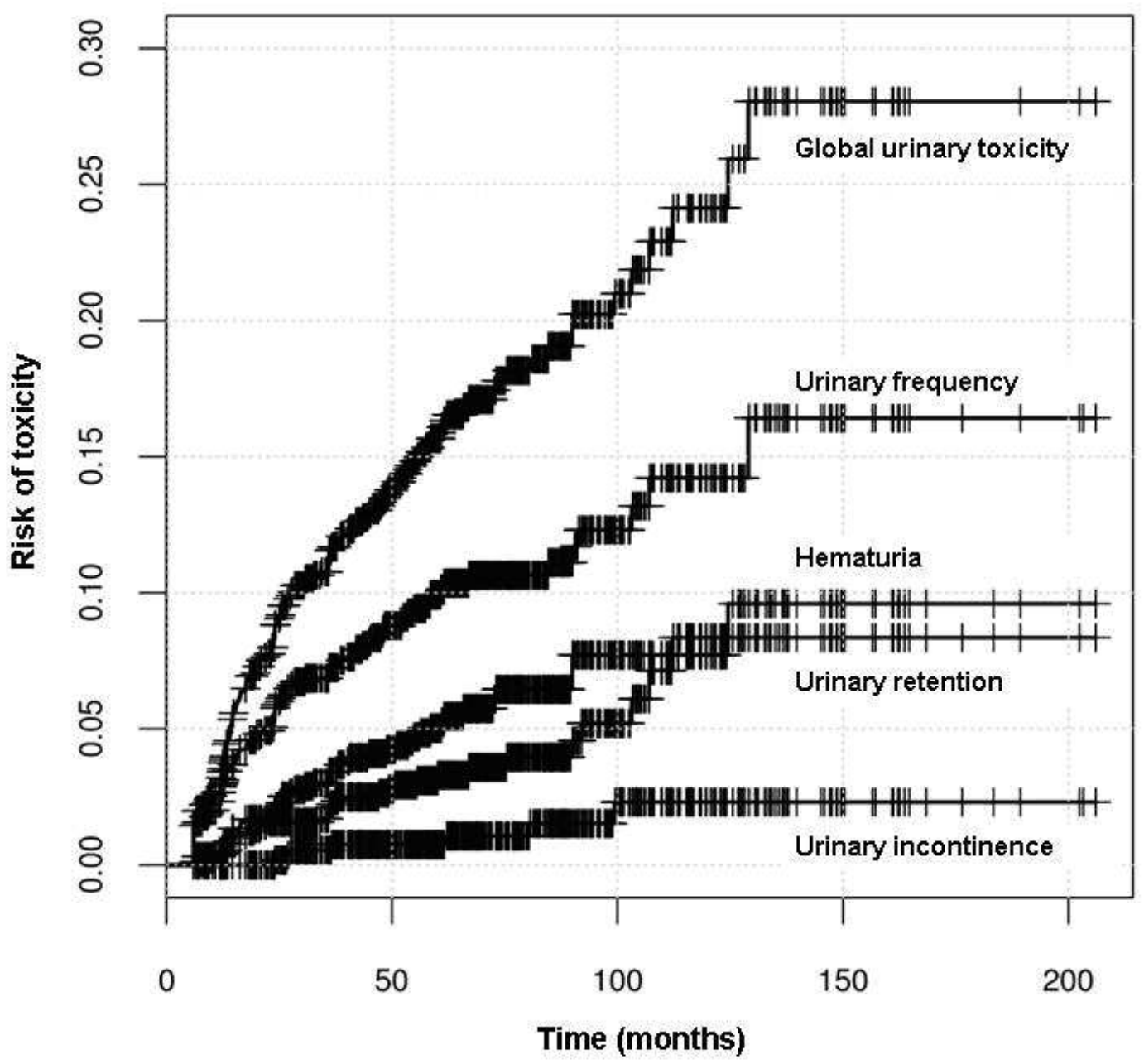

414

415 Figure1: Incidence of global and by symptoms late urinary toxicity ( $\geq$ grade 2)

416 according to LENTSOMA classification

417 
Points

Anticoagulant

treatment

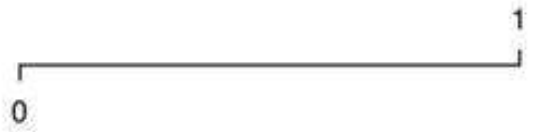

Total dose (Gy)

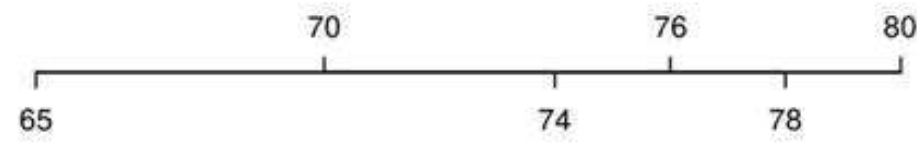

Total points

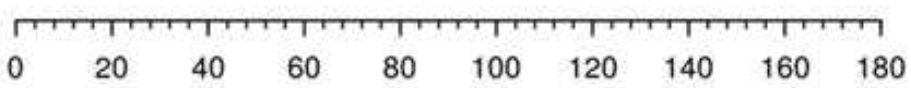

Risk
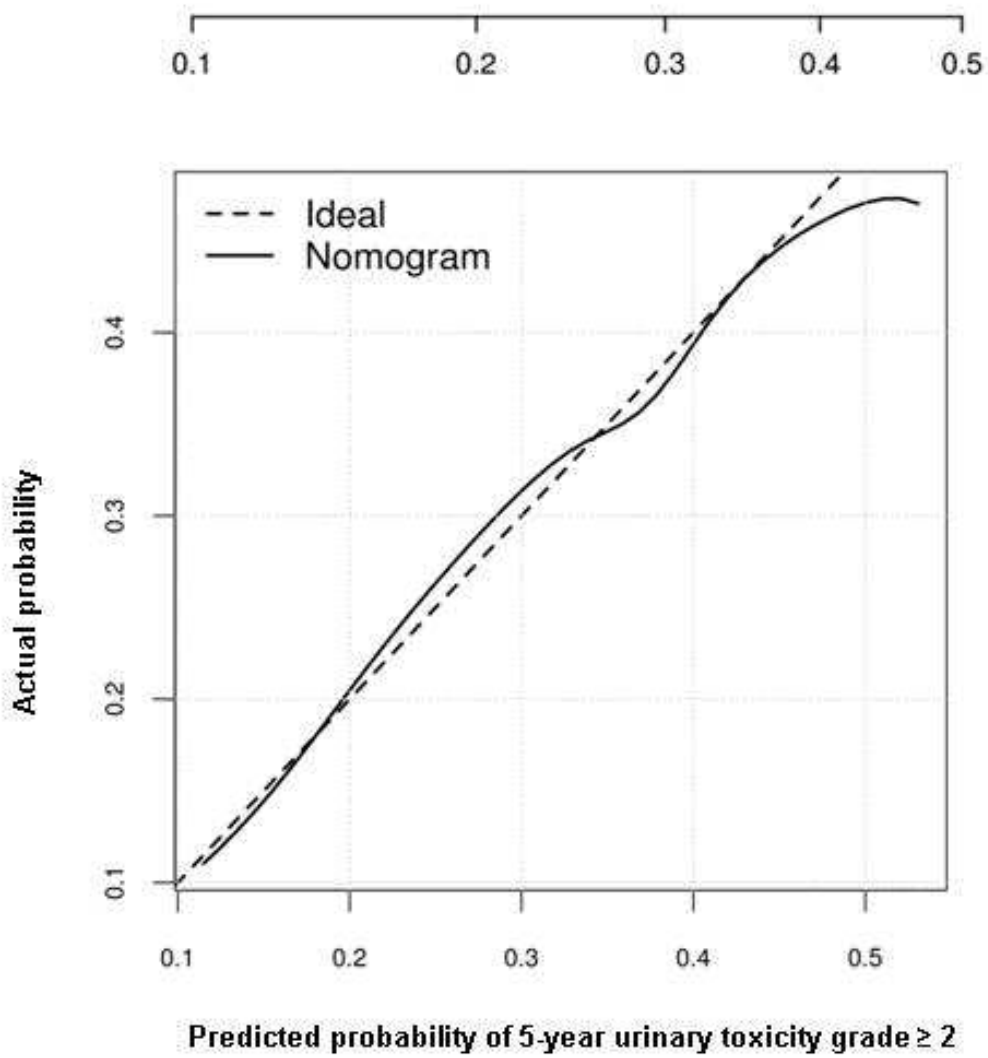

418

419 Figure 2: Five-year risk of global late urinary toxicity grade $\geq 2$ : nomogram and

420 calibration plot

421 Calibration plot assessing the nomogram performance by a nonparametric fit of the 
422 predicted probability versus the actual observed probability.

423

Points

$\begin{array}{lllllllllll}0 & 10 & 20 & 30 & 40 & 50 & 60 & 70 & 80 & 90 & 100\end{array}$

Diabetes

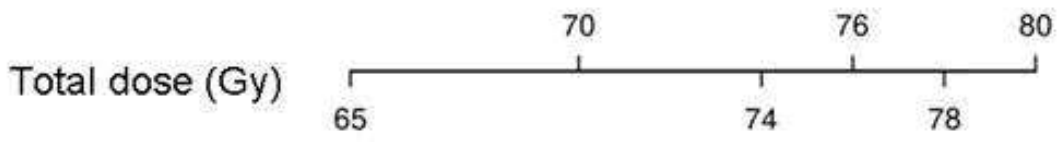

Total points

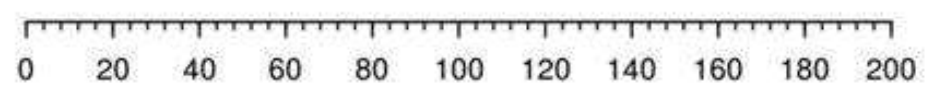

Risk
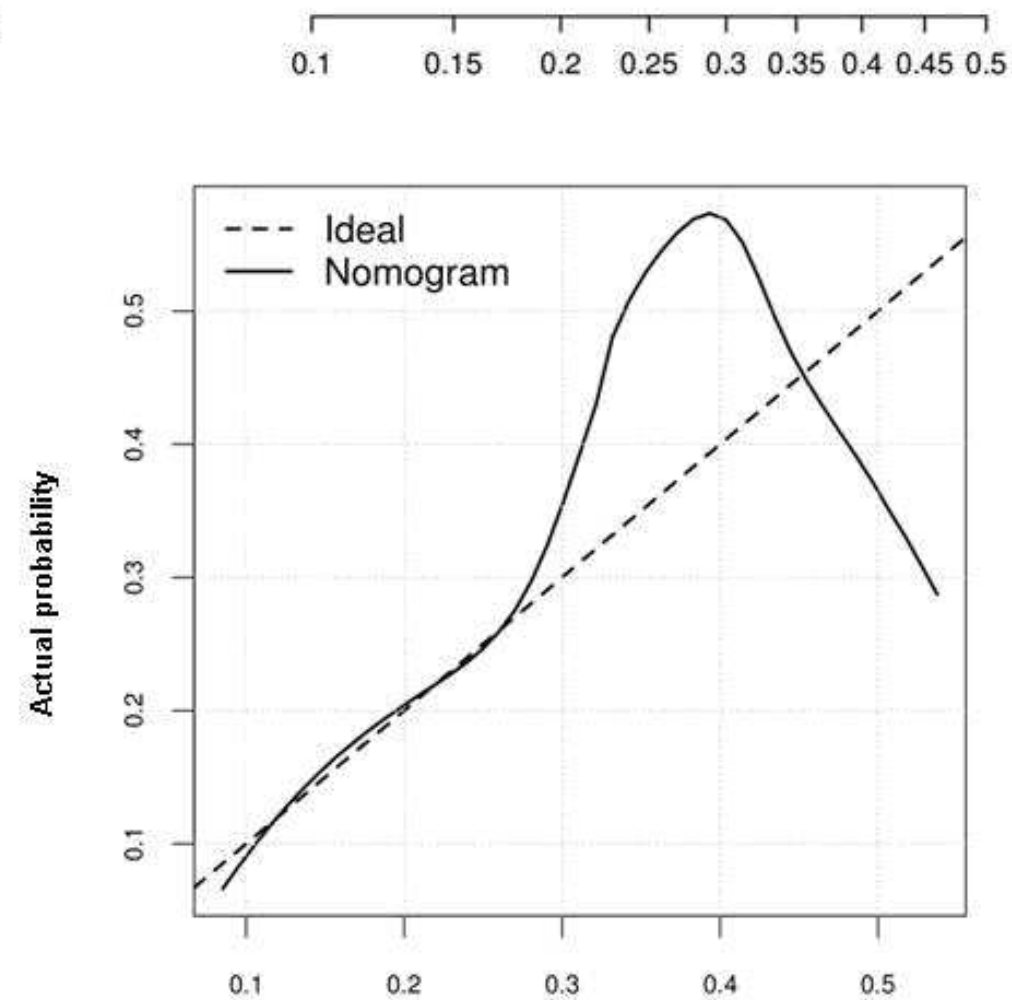

Predicted probability of 5 -year urinary frequency grade $\geq 2$

424

425 Figure 3: Five-year risk of urinary frequency grade $\geq 2$ : nomogram and 
427 Calibration plot assessing the nomogram performance by a nonparametric fit of the 428 predicted probability versus the actual observed probability.

Points
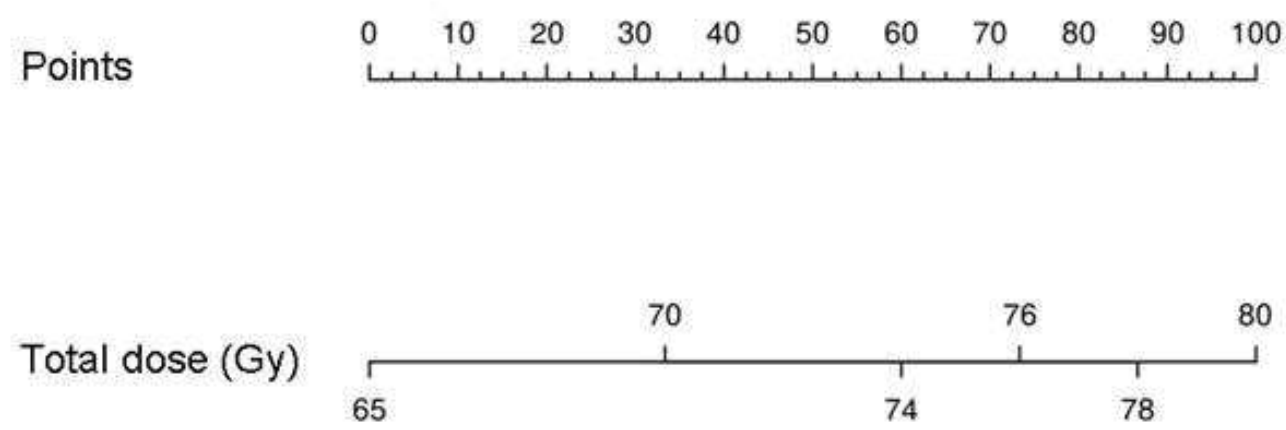

Total points

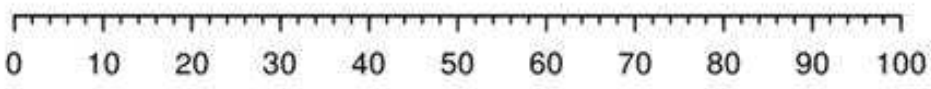

Risk

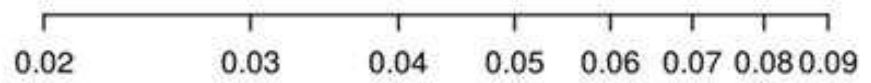

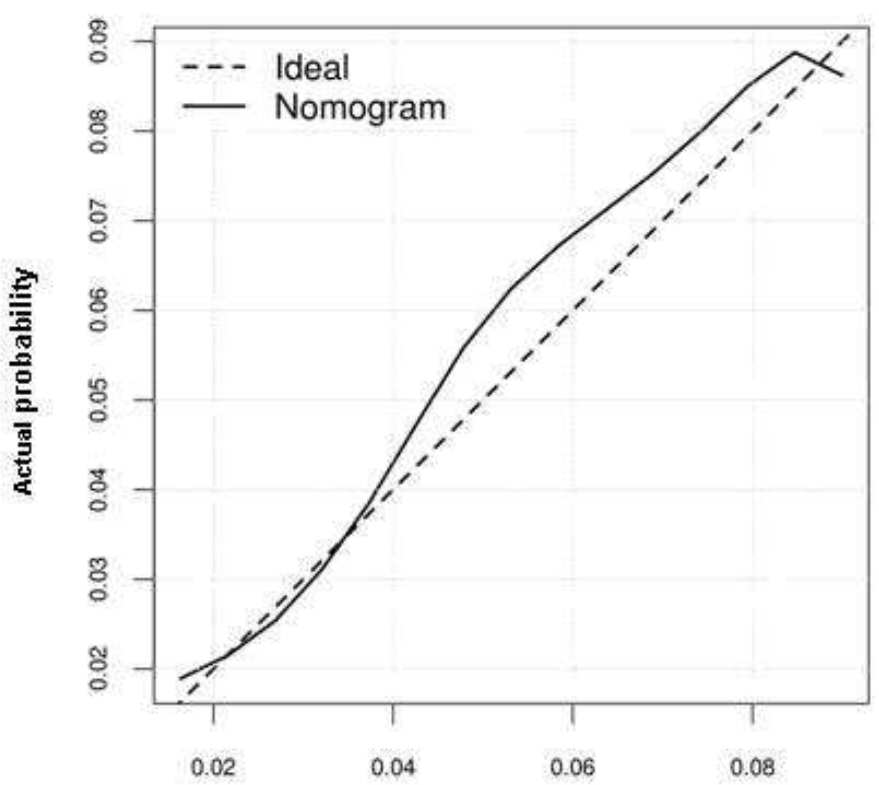

Predicted probability of 5 -year urinary retention grade $\geq 2$ 
430 Figure 4: Five-year risk of dysuria grade $\geq 2$ : nomogram and calibration plot

431 Calibration plot assessing the nomogram performance by a nonparametric fit of the 432 predicted probability versus the actual observed probability.

433

434 


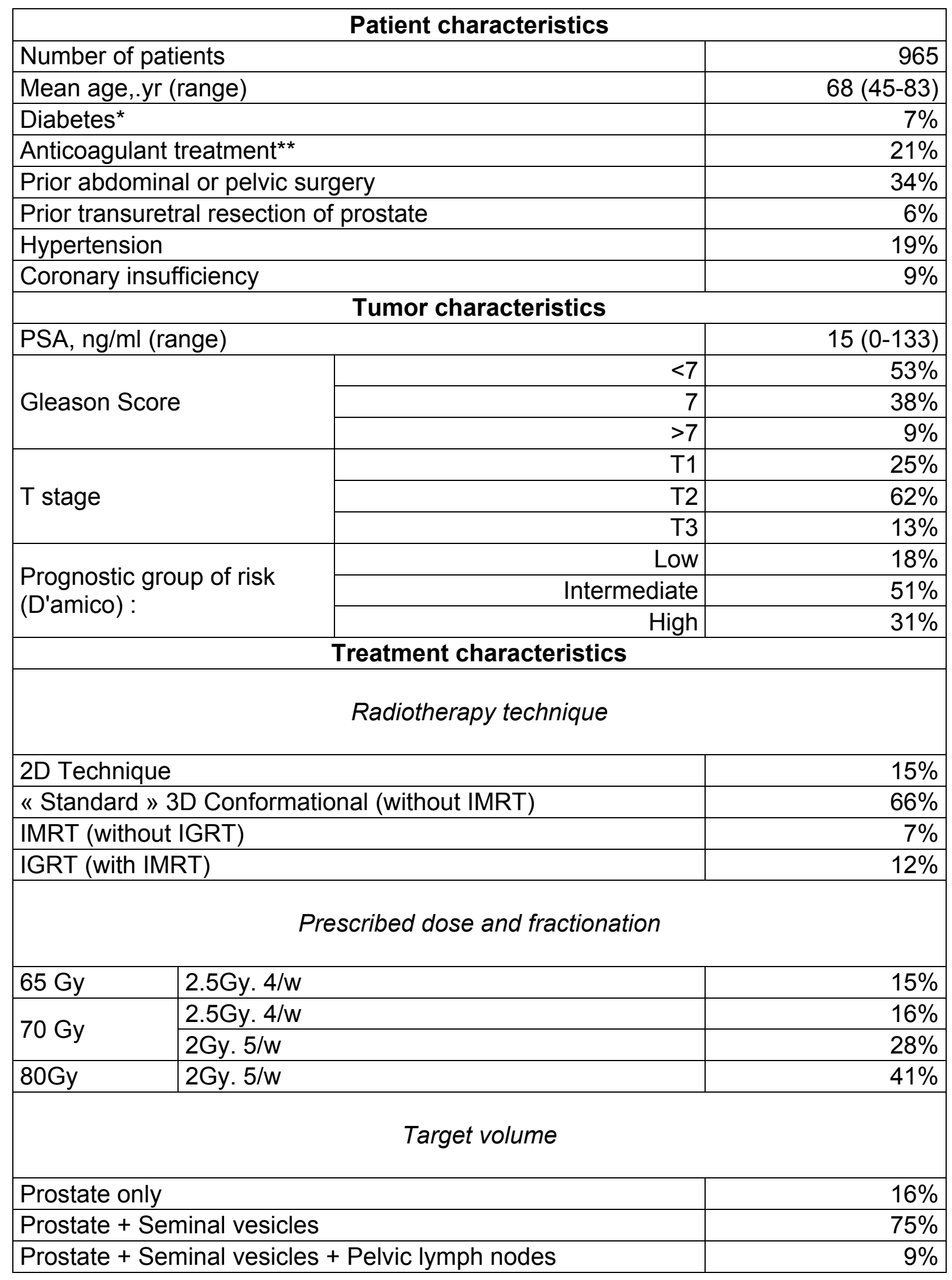




\begin{tabular}{|c|c|c|}
\hline \multicolumn{3}{|c|}{ Dosimetric parameters } \\
\hline \multirow{4}{*}{$\begin{array}{l}\text { Bladder } \\
\left(\text { wall }{ }^{\star \star \star}\right)\end{array}$} & Volume (cc) +/- SD & $70,7+/-39,5$ \\
\hline & $\operatorname{Dmax}(\mathrm{Gy})+/-\mathrm{SD}$ & $75,8+/-4,7$ \\
\hline & D25 (Gy) +/- SD & $64,8+/-11,6$ \\
\hline & D50 (Gy) +/- SD & $43,1+/-15,2$ \\
\hline \multirow{3}{*}{ Target } & PTV prostate and SV (cc) +/- SD & $234,5+/-60,9$ \\
\hline & PTV prostate only (cc) +/- SD & $174,2+/-55,6$ \\
\hline & V95 (\%)+/- SD & $93,1+/-10,8$ \\
\hline \multicolumn{2}{|c|}{ Androgen deprivation (concomitant and adjuvant) } & $23 \%$ \\
\hline
\end{tabular}

439 Yr: year, * type 1 or $2,{ }^{* *}$ vitamin $\mathrm{K}$ antagonist and antiplatelet drugs, W: week, SD:

440 Standard Deviation, ${ }^{* * *}$ thickness of bladder wall $=7 \mathrm{~mm}$, Dmax: maximum dose, D25:

441 minimal dose received in $25 \%$ of the bladder wall volume, D50: minimal dose

442 received in $50 \%$ of the bladder wall volume, PTV: planning target volume, V95:

443 volume of the prostate-PTV (in \%) receiving 95\% of the prescribed dose. 
Table 2: LENTSOMA grading scale (Urinary symptoms)

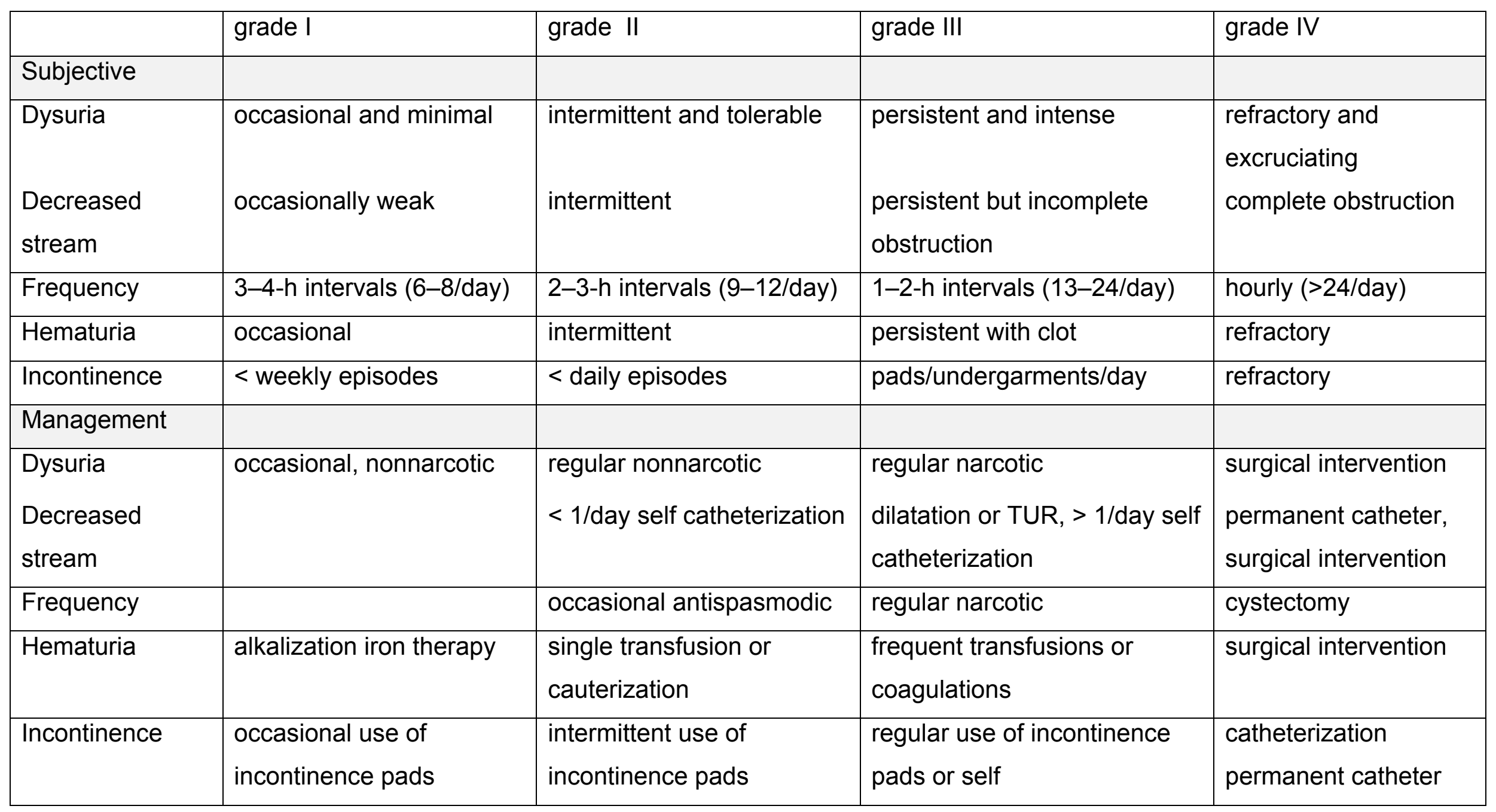


Table 3: Patient, tumor and treatment factors related to five year risk of late urinary toxicity and corresponding symptoms (multivariate regression logistic analysis)

\begin{tabular}{|c|c|c|c|c|c|c|c|c|}
\hline \multirow[b]{2}{*}{ Factors } & \multicolumn{2}{|l|}{ Late urinary toxicity } & \multicolumn{2}{|l|}{ Urinary frequency } & \multicolumn{2}{|l|}{ Hematuria } & \multicolumn{2}{|l|}{ Dysuria } \\
\hline & $\operatorname{RR}(95.0 \% \mathrm{Cl})$ & $\begin{array}{l}\mathrm{p} \\
\text { value }\end{array}$ & $\mathrm{RR}(95.0 \% \mathrm{Cl})$ & $\begin{array}{l}\mathrm{p} \\
\text { value }\end{array}$ & $\operatorname{RR}(95.0 \% \mathrm{Cl})$ & $\begin{array}{l}p \\
\text { value }\end{array}$ & $\mathrm{RR}(95.0 \% \mathrm{Cl})$ & $\begin{array}{l}p \\
\text { value }\end{array}$ \\
\hline $\begin{array}{l}\text { Anticoagulant } \\
\text { treatment }\end{array}$ & $2.35(1.33-4.14)$ & $<0.01$ & - & - & $2.89(1.29-6.46)$ & 0.01 & - & - \\
\hline Total dose & $1.09(1.05-1.14)$ & $<0.01$ & $1.07(1.02-1.13)$ & 0.01 & - & - & $1.10(1.02-1.17)$ & 0.01 \\
\hline Diabetes & - & - & $4.00(1.42-11.27)$ & 0.01 & - & - & - & - \\
\hline $\mathrm{D} 25$ & 1.03 (1.00-1.06) & 0.04 & - & & - & - & - & - \\
\hline Dmax & $1.10(1.04-1.17)$ & $<0.01$ & - & & - & - & - & - \\
\hline Age & $1.06(1.01-1.11)$ & 0.02 & - & & - & - & - & - \\
\hline
\end{tabular}

$\mathrm{Cl}$ : confidence interval, RR: relative risk, $p$ value $\leq 0.05$ was considered statistically significant. D25: minimal dose received in $25 \%$ of the bladder wall volume.

Following parameters have been tested in the model: age, diabetes, anticoagulant treatment, prior abdominal surgery, prior transurethral resection of prostate, hypertension, coronary insufficiency, gleason score, T stage, prognostic group of risk (D'amico), 
RT technique (2D, Conformational 3D with or without IMRT/IGRT), total dose and fractionation, target volume, dose received by the bladder (maximal dose, D25, D50), and androgen deprivation. 